\title{
Relationship between New Osteoporotic Vertebral Fracture and Instrumented Lumbar Arthrodesis
}

\author{
Bung-Hak Kim, Dong-Hyuk Choi, Seong-Hun Jeon, Yong-Soo Choi \\ Department of Orthopaedics, Kwangju Christian Hospital, Gwangju, Korea
}

\begin{abstract}
Study Design: Retrospective study.
Purpose: To evaluate the relationship between a new osteoporotic vertebral fracture and instrumented lumbar arthrodesis. Overview of Literature: In contrast to the growing recognition of the importance of adjacent segment disease after lumbar arthrodesis, relatively little attention has been paid to the relationship between osteoporotic vertebral fractures and instrumented lumbar arthrodesis.

Methods: Twenty five patients with a thoracolumbar vertebral fracture following instrumented arthrodesis for degenerative lumbar disorders (study group) were investigated. The influence of instrumented lumbar arthrodesis was examined by com paring the bone mineral density (BMD) of the femoral neck in the study group with that of 28 patients (control group) who had sustained a simple osteoporotic vertebral fracture. The fracture after instrumented arthrodesis was diagnosed at a mean 47 months (range, 7 to 100 months) after the surgery.

Results: There was a relatively better BMD in the study group, $0.67 \pm 0.12 \mathrm{~g} / \mathrm{cm}^{2}$ compared to the control group, $0.60 \pm$ $0.13 \mathrm{~g} / \mathrm{cm}^{2}(p=0.013)$. The level of back pain improved from a mean of $7.5 \pm 1.0$ at the time of the fracture to a mean of 4.9 \pm 2.0 at 1 year after the fracture $(p=0.001)$. However, $12(48 \%)$ patients complained of severe back pain 1 year after the fracture. There was negative correlation between the BMD of the femoral neck and back pain at the last follow up $(r=-$ $0.455, p=0.022$ ).

Conclusions: Osteoporotic vertebral fractures after instrumented arthrodesis contribute to the aggravation of back pain and the final outcome of degenerative lumbar disorders. Therefore, it is important to examine the possibility of new osteoporotic vertebral fractures for new-onset back pain after lumbar instrumented arthrodesis.
\end{abstract}

Key Words: Lumbar spine, Vertebral fracture, Osteoporosis, Instrumented arthrodesis

\section{Introduction}

Vertebral compression fractures are a common and often debilitating complication of osteoporosis. Percutaneous vertebroplasty is a minimally invasive procedure that provides prompt pain relief with a low complication rate. Vertebral fractures increase significantly the lifetime risk of further fractures, and new vertebral fractures at the adjacent or nonadjacent vertebrae can occur repeatedly after vertebroplasty. The mechanism of the new vertebral fractures is unclear, but from experimental and computational studies, it appears that a change in the mechanical load after augmentation might be responsible [1-8]. If the adjacent vertebrae are already rigid, the dynamic hammer effect can lead to a nonadjacent fracture [9].

Received Jan 22, 2010; 1st Revised Feb 22, 2010; Accepted Mar 15, 2010

Corresponding author: Yong-Soo Choi, MD

Department of Orthopaedic Surgery, Kwangju Christian Hospital,

Yangnim-dong, Nam-gu, Gwangju 503-715, Korea

Tel: +82-62-650-5064, Fax: +82-62-650-5066, E-mail: stemcellchoi@yahoo.co.kr 
In contrast to the growing recognition of the importance of adjacent segment disease after lumbar arthrodesis, relatively little attention has been paid to the relationship between osteoporotic vertebral fractures and instrumented lumbar arthrodesis. Solid fusion alters the biomechanics at the motion segments, resulting in increased mechanical demand. Increased biomechanical forces, mobility and intradiscal pressure in the adjacent and non-adjacent segments after fusion have been suggested to accelerate these pathological changes [10-14]. One of the findings next to a fused segment was vertebral compression fractures [15]. There is limited data available on incidence of new osteoporotic vertebral fractures after lumbar spine fusion [16]. The ability of the vertebral body to carry a load depends on the structural capacity of the vertebrae and on the loading conditions that arise from the activities of daily living or trauma. The vertebral bone in an aging spine fails because it cannot support the internal stresses and strains that result from loads applied to the vertebral body [17]. It is possible to sustain a new vertebral fracture at the osteoporotic vertebra because instrumented lumbar arthrodesis alters the biomechanics of load transfer to the remained vertebrae. Therefore, this study examined the relationship between a new osteoporotic vertebral fracture and instrumented lumbar arthrodesis.

\section{Materials and Methods}

\section{Materials}

The charts and radiographs of 30 consecutive patients who developed a new osteoporotic vertebral fracture among 201 patients who underwent instrumented arthrodesis for degenerative lumbar disorders from July 2000 to July 2007 were reviewed retrospectively. Five patients were excluded because they were not followed up for more than 1 year or had multiple fractures. Twenty five patients were classified into the study group. The mean age of the study group was 64.7 years (range, 48 to 83 years). Six patients were men and 19 patients were women. Instrumented arthrodesis was performed for spinal stenosis, spondylolisthesis and herniated nucleus pulposus in 17, 7 and 1 case, respectively. The mean fusion levels of the degenerative lumbar disorders were 1.84 segments (range, 1 to 3 segments). To determine the effect of the bone mineral density, 28 patients with a simple osteoporotic compression fracture at one vertebra in 2007 were investigated as a control group. The mean age of the control group was 69.3 years (range, 47 to 83 years). Six patients were men and 22 patients were women.

The osteoporotic vertebral fracture in both groups was treated with bed rest and pain medication in the early stages. After resolving the extreme pain, early ambulation with a brace was recommended. If the pain continued for more than 2 or 3 weeks, vertebroplasty was performed with bone cement in 2 cases (Fig. 1). After 8 to 12 weeks of brace application, muscle strengthening exercise and reforming the mode of living and osteoporotic medication were recommended.

\section{Methods}

The bone mineral density of the femoral neck in the study group was compared with that of the control group. The changes in back pain and the radiographic results of the study group were analyzed.

\section{(1) Clinical evaluation}

The clinical results, including the visual analogue score (VAS) of back pain were investigated before the fracture, after the fracture and at the 1 year follow-up. The back pain score was recorded from 0 (no pain) to 10 (extreme pain).

\section{(2) Radiographic evaluation}

Vertebral height loss and lumbar lordosis were measured at the time of the fracture and at the final follow up. The vertebral height loss was calculated by anterior compression of the fractured vertebra divided by the mean of the anterior column length of the adjacent vertebra. The lumbar lordosis was estimated by Cobb's method using the L1 and S1 end plate.

\section{(3) Statistical analysis}

The data is expressed as the mean \pm standard deviation. Statistical analyses were performed using SPSS ver. 12.0 (SPSS Inc., Chicago, IL, USA). The differences in age, body weight, and bone mineral density between both groups were examined using a $t$-test. A Wilcoxon signed-ranks test was used to determine changes in back pain (VAS score) at the time of the fracture and at 1 year after the fracture. Radiological changes in vertebral height and lumbar lordosis between the time of fracture and 1 year after the fracture were examined using a paired $t$-test. Finally, the correlations between back pain and the results from the loss of vertebral height, lumbar lordosis, and the bone mineral density 

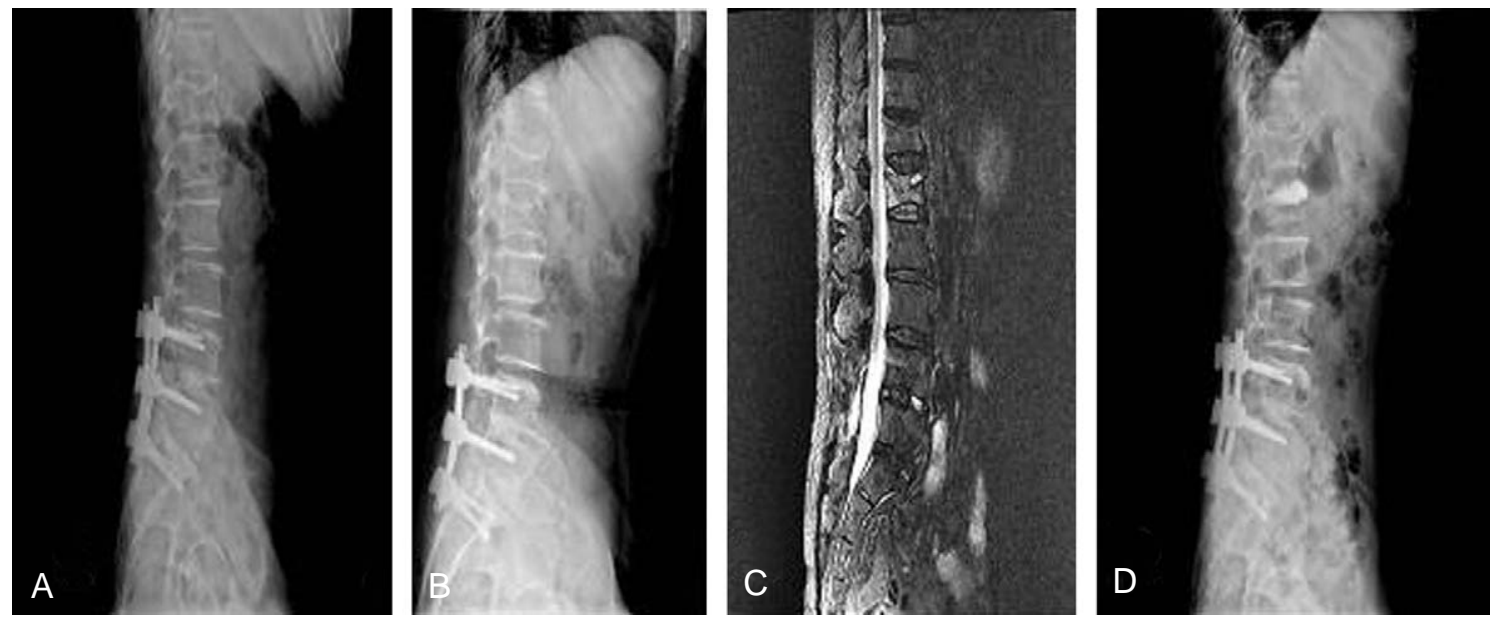

Fig. 1. A 66-year-old female radiographs. (A) Instrumented posterior lumbar interbody fusion was done for spinal stenosis. (B) At postoperative 16months, L1 compression fracture was developed after slip down. (C) Lumbar magnetic resonance imaging with T2 image shows signal change at L1 body. (D) Kyphoplasty was done at L1 body because of continuous back pain in spite of conservative therapy.

(BMD) of femoral neck were analyzed.

\section{Results}

The clinically diagnosed vertebral fractures in the study group were associated with a slip down in 6 cases, back strain in one case and the aggravation of back pain without trauma in 18 cases. In the control group, the patient history showed a slip down in 7 cases, back strain in 2 cases and the aggravation of back pain without trauma in 19 cases. There was a better BMD in the study group than the control group $\left(0.67 \pm 0.12 \mathrm{~g} / \mathrm{cm}^{2}\right.$ vs. $0.60 \pm 0.13 \mathrm{~g} / \mathrm{cm}^{2}, p=$ $0.013)$. The fracture following instrumented arthrodesis was diagnosed after a mean of 47 months (range, 7 to 100 months). Fractures in the study group were found at T11, T12, L1, L2 and L3 in 6, 7, 7, 4, and 1 case, respectively. In the control group, the fracture site was found in T8, T11, T12, L1, L2, L3 and L4 in 1, 1, 5, 12, 6, 2, and 1 case, respectively. There was no difference in the fracture site between both groups.

The VAS score for back pain was $4.6 \pm 1.4$ before the fracture. The VAS score improved from a mean of $7.5 \pm$ 1.0 at the time of the fracture to a mean of $4.9 \pm 2.0$ at 1 year after the fracture $(p=0.001)$. However, 12 patients $(48 \%)$ complained of an aggravation of back pain 1 year after the fracture compared to the pre-fracture state.

Height loss of the fracture showed a mean of $24.1 \pm$ $12.1 \%$ at the time of the fracture and $24.3 \pm 12.1 \%, 24.2$ $\pm 10.1^{\circ}$ at 1 year after the fracture. The lumbar lordosis

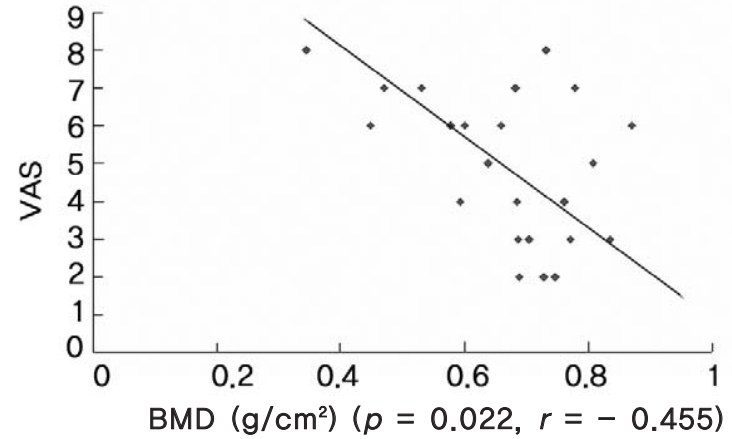

Fig. 2. There was a statistically negative correlation between the bone mineral density (BMD) of femoral neck and the back pain at the last follow up $(r=-0.455, p=0.022)$. VAS: Visual analogue score.

revealed an average of $22.8 \pm 10.9^{\circ}$ at the time of the fracture and $24.2 \pm 10.1^{\circ}$ at 1 year after fracture. There was no significant change in radiological height loss of the fracture and lumbar lordosis at 1 year after the fracture. In addition, there was no significant correlation between back pain and the loss of vertebral height $(r=-0.198, p=0.342)$, back pain and lumbar lordosis $(r=0.070, p=0.741)$ at the last follow up. On the other hand, there was significant negative correlation between the BMD of the femoral neck and back pain at the last follow up $(r=-0.455, p=0.022)$ (Fig. 2).

\section{Discussion}

Given the number of spinal fusions performed annually, there has been increasing concern regarding the potential for adjacent segment degeneration, radiographic changes in 
degeneration at the levels adjacent to the spinal fusion, adjacent segment disease, and the development of new symptoms associated with adjacent segment degeneration. Osteoporotic vertebral fractures may be a sentinel sign of failing health in elderly patients, and are likely to become an increasing health-care concern as the population continues to age. We wondered whether an osteoporotic vertebral fracture develops through an increased biomechanical load on the vertebrae adjacent to the fusion sites.

A decrease in the number, thickness and interconnectivity of vertebral trabeculae in combination with altered load transmission across the degenerated disc predisposes the vertebral body to fracture from minor trauma. Biomechanically, compressive forces in the vertebra are transferred from the intervertebral discs to the vertebral endplates and are then distributed between the trabecular centrum and the thin shell of condensed bone that comprise the vertebral body. Most of the axial force is carried out by the trabecular bone [18-21]. Therefore, the axial forces external to the vertebra impart stresses and strains to the trabecular centrum. The ultimate strength of the trabecular bone is determined by the maximum stress that it can sustain within the overall structure of the vertebral body. The trabecular bone, particularly osteoporotic vertebra, will fail if the strength is not greater than the working stresses in the vertebra under physiological or traumatic conditions. Such local failures or cracks can lead to a fracture of the entire bone. Therefore, strength is an important mechanical property when considering the risk of fracture.

The total flexibility of the lumbar spine was decreased after lumbar fusion. There was less segmental deformation of the juxta-fused segments after either a single-or doublelevel fusion. During lumbar motion, the remaining segments were not deformed beyond their physiological limits after fusion. However, the percentage mechanical load at the un-fused segments was increased due to the reduced number of motion segments for mechanical load-sharing [22]. The thoracolumbar junction connects the relatively rigid, kyphotic thoracic spine, which is stabilized by the rib cage to the more mobile, lorodotic un-fused vertebrae. This transitional zone might experience substantial biomechanical stresses during minor trauma, such as slip down, back strain and the activities of daily living, which make it more susceptible to fractures than adjacent segment disease. Most osteoporotic vertebral fractures affected the motion segments between $\mathrm{T} 11$ and $\mathrm{L} 2$ in both groups.

In this study, the study group had a better BMD than the control group $\left(0.67 \pm 0.12 \mathrm{~g} / \mathrm{cm}^{2}\right.$ vs. $0.60 \pm 0.13 \mathrm{~g} / \mathrm{cm}^{2}, p$ $=0.013)$. However, a vertebral fracture after instrumented fusion occurred at a mean 47 months after lumbar fusion. The fracture was noted at the thoracolumbar junction in contrast to adjacent segment disease. At the remaining vertebra with a degenerated disc, the loads are transmitted unevenly to the end plates, resulting in possible load concentrations on parts of the end plate [23]. A fracture results when this load overcomes the resistance of the fragile end plate.

It is unclear why the lumbar spine cannot be used to measure the BMD instead of the femoral neck BMD. The BMD is normally measured at the lumbar spine and proximal femur because these sites are affected early in the course of osteoporosis and are the most common sites of osteoporotic fractures [24-26]. Measurements of the lumbar spine BMD for an osteoporotic vertebral fracture could be necessary because the femoral neck BMD cannot predict the lumbar spine BMD precisely [27]. Unfortunately, the BMD could not be measured at the lumbar spine because of lumbar fusion with instrumentation. Black et al. [28] reported that the decreased bone density measurements in the hip, spine, and extremities were equally predictive of the increased fracture risk in older women.

This study is limited by the small number of cases and lack of a comparison of fusion level and fusion methods. To provide more evidence for the influence of instrumented lumbar arthrodesis on the osteoporotic vertebral fracture, it will be necessary to run additional studies such as comparison of fusion level and fusion methods with prospective design.

\section{Conclusions}

These results suggest that an osteoporotic vertebral fracture after instrumented arthrodesis can aggravate back pain and affect the final outcome of degenerative lumbar disorders. Therefore, it is important to evaluate the possibility of a new osteoporotic vertebral fracture when new-onset back pain occurs after lumbar instrumented arthrodesis.

\section{REFERENCES}

1. Wilcox RK. The biomechanical effect of vertebroplasty on the adjacent vertebral body: a finite element study. Proc 
Inst Mech Eng H 2006;220:565-72.

2. Boger A, Heini P, Windolf M, Schneider E. Adjacent vertebral failure after vertebroplasty: a biomechanical study of low-modulus PMMA cement. Eur Spine J 2007;16:211825.

3. Furtado N, Oakland RJ, Wilcox RK, Hall RM. A biomechanical investigation of vertebroplasty in osteoporotic compression fractures and in prophylactic vertebral reinforcement. Spine (Phila Pa 1976) 2007;32:E480-7.

4. Farooq N, Park JC, Pollintine P, Annesley-Williams DJ, Dolan P. Can vertebroplasty restore normal load-bearing to fractured vertebrae? Spine (Phila Pa 1976) 2005;30:172330.

5. Baroud G, Nemes J, Heini P, Steffen T. Load shift of the intervertebral disc after a vertebroplasty: a finite-element study. Eur Spine J 2003;12:421-6.

6. Keller TS, Kosmopoulos V, Lieberman IH. Vertebroplasty and kyphoplasty affect vertebral motion segment stiffness and stress distributions: a microstructural finite-element study. Spine (Phila Pa 1976) 2005;30:1258-65.

7. Baroud G, Vant C, Wilcox R. Long-term effects of vertebroplasty: adjacent vertebral fractures. J Long Term Eff Med Implants 2006;16:265-80.

8. Berlemann U, Ferguson SJ, Nolte LP, Heini PF. Adjacent vertebral failure after vertebroplasty: a biomechanical investigation. J Bone Joint Surg Br 2002;84:748-52.

9. Ahn Y, Lee JH, Lee HY, Lee SH, Keem SH. Predictive factors for subsequent vertebral fracture after percutaneous vertebroplasty. J Neurosurg Spine 2008;9:129-36.

10. Cheh G, Bridwell KH, Lenke LG, et al. Adjacent segment disease following lumbar/thoracolumbar fusion with pedicle screw instrumentation: a minimum 5-year follow-up. Spine (Phila Pa 1976) 2007;32:2253-7.

11. Kumar A, Beastall J, Hughes J, et al. Disc changes in the bridged and adjacent segments after Dynesys dynamic stabilization system after two years. Spine (Phila Pa 1976) 2008;33:2909-14.

12. Kumar MN, Baklanov A, Chopin D. Correlation between sagittal plane changes and adjacent segment degeneration following lumbar spine fusion. Eur Spine J 2001;10:314-9.

13. Lai PL, Chen LH, Niu CC, Fu TS, Chen WJ. Relation between laminectomy and development of adjacent segment instability after lumbar fusion with pedicle fixation. Spine (Phila Pa 1976) 2004;29:2527-32.

14. Lehmann TR, Spratt KF, Tozzi JE, et al. Long-term followup of lower lumbar fusion patients. Spine (Phila Pa 1976) 1987;12:97-104.
15. Park P, Garton HJ, Gala VC, Hoff JT, McGillicuddy JE. Adjacent segment disease after lumbar or lumbosacral fusion: review of the literature. Spine (Phila Pa 1976) 2004; 29:1938-44.

16. Hart RA, Prendergast MA, Roberts WG, Nesbit GM, Barnwell SL. Proximal junctional acute collapse cranial to multi-level lumbar fusion: a cost analysis of prophylactic vertebral augmentation. Spine J 2008;8:875-81.

17. Myers ER, Wilson SE. Biomechanics of osteoporosis and vertebral fracture. Spine (Phila Pa 1976) 1997;22(24 Suppl):25S-31S.

18. McBroom RJ, Hayes WC, Edwards WT, Goldberg RP, White AA 3rd. Prediction of vertebral body compressive fracture using quantitative computed tomography. J Bone Joint Surg Am 1985;67:1206-14.

19. Silva MJ, Keaveny TM, Hayes WC. Load sharing between the shell and centrum in the lumbar vertebral body. Spine (Phila Pa 1976) 1997;22:140-50.

20. Silva MJ, Wang C, Keaveny TM, Hayes WC. Direct and computed tomography thickness measurements of the human, lumbar vertebral shell and endplate. Bone 1994;15:409-14.

21. Yoganandan N, Mykiebust JB, Cusick JF, Wilson CR, Sances A Jr. Functional biomechanics of the thoracolumbar vertebral cortex. Clin Biomech 1988;3:11-8.

22. Luk KD, Chow DH, Evans JH, Leong JC. Lumbar spinal mobility after short anterior interbody fusion. Spine (Phila Pa 1976) 1995;20:813-8.

23. Kurowski P, Kubo A. The relationship of degeneration of the intervertebral disc to mechanical loading conditions on lumbar vertebrae. Spine (Phila Pa 1976) 1986;11:726-31.

24. Orwoll ES, Oviatt SK, Mann T. The impact of osteophytic and vascular calcifications on vertebral mineral density measurements in men. J Clin Endocrinol Metab 1990;70: 1202-7.

25. Dawson-Hughes B, Dallal GE. Effect of radiographic abnormalities on rate of bone loss from the spine. Calcif Tissue Int 1990;46:280-1.

26. Laitinen K, Välimäki M, Keto P. Bone mineral density measured by dual-energy X-ray absorptiometry in healthy Finnish women. Calcif Tissue Int 1991;48:224-31.

27. Yang SO, Lee YI, Chung DH, Lee JM, Oh JY. Necessity of site-specific BMD measurements using dual X-ray absorptiometry. J Korean Radiol Soc 1995;32:971-4.

28. Black DM, Cummings SR, Genant HK, Nevitt MC, Palermo L, Browner W. Axial and appendicular bone density predict fractures in older women. J Bone Miner Res 1992;7:633-8. 